
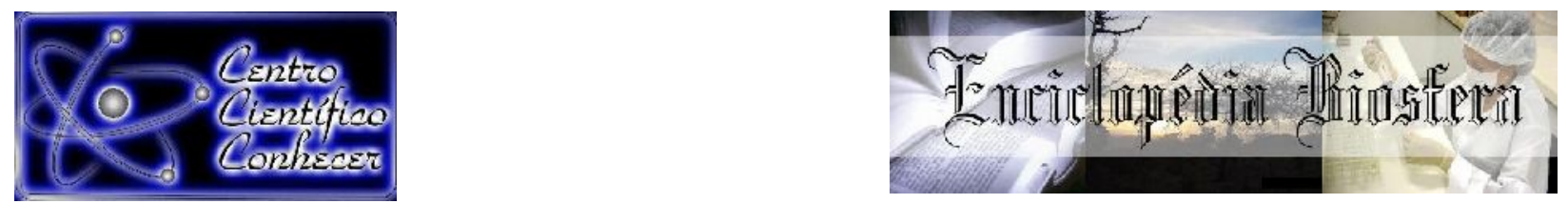

\title{
MONITORAMENTO DA ARBORIZAÇÃO URBANA POR SENSORIAMENTO REMOTO EM UM MUNICÍPIO INSERIDO NO SEMIÁRIDO BRASILEIRO
}

\begin{abstract}
Alana Oliveira de Andrade1, Rodrigo José de Carvalho Lopes², Regina Lúcia Félix de Aguiar Lima ${ }^{3}$, Rosimary de Carvalho Gomes Moura ${ }^{4}$, Claudemiro de Lima Júnior ${ }^{3}$

'Licenciada em Ciências Biológicas pela Universidade de Pernambuco (UPE), Campus Universitário - Cidade universitária, CEP 56.300-000, Petrolina -

Pernambuco

${ }^{2}$ Licenciado em Geografia pela Universidade de Pernambuco (UPE), Programa de

Pós-Graduação em Ciência e Tecnologia Ambiental (PPGCTA), Campus

Universitário - Cidade universitária, CEP 56.300-000, Petrolina -Pernambuco

${ }^{3}$ Professora adjunta da Universidade de Pernambuco Campus Petrolina, Programa

de Pós-Graduação em Ciência e Tecnologia Ambiental (PPGCTA), Campus

Universitário - Cidade Universitária, CEP 56.300-000, Petrolina -Pernambuco

${ }^{4}$ Professora adjunta da Universidade de Pernambuco Campus Petrolina, Colegiado de Licenciatura em Ciências Biológicas, Campus Universitário - Cidade Universitária, CEP 56.300-000, Petrolina -Pernambuco

${ }^{3}$ Professor adjunto da Universidade de Pernambuco Campus Petrolina, Programa de

Pós-Graduação em Ciência e Tecnologia Ambiental (PPGCTA), Campus Universitário - Cidade Universitária, CEP 56.300-000, Petrolina -Pernambuco, Email: claudemiro.lima@upe.br
\end{abstract}

Recebido em: 15/05/2021 - Aprovado em: 15/06/2021 - Publicado em: 30/06/2021 DOI: 10.18677/EnciBio_2021B17

Há muitas formas de se proporcionar interação entre a sociedade no meio urbano, como os "espaços verdes arbóreos" que são conceituadas como espaço livre urbano, composto por vegetação arbórea e arbustiva que proporcionam amenização dos impactos ambientais da urbanização, onde pelo menos $70 \%$ da área seja permeável e acessível à população. Assim, nesse estudo objetivou-se avaliar o uso do sensoriamento remoto, a partir de imagens de satélite, para caracterizar os espaços verdes arbóreos de Petrolina, um município inserido no Semiárido brasileiro. A avaliação foi feita com uso de imagens orbitais, classificadas pela técnica de segmentação e validadas. A seguir, foram quantificadas as áreas verdes e calculado o índice de área verde. Nesse cálculo incluem-se todas as áreas verdes, com plantas nativas ou não, que são consideradas na composição da arborização na cidade de Petrolina para obtenção do lazer, conforto térmico ou arquitetura urbanística. O índice mostrou que há $18,827 \mathrm{~m}^{2}$ de área verde para cada habitante da cidade, sendo considerado alto para a realidade da área estudada, e isso ocorre, devido aos critérios para categorização das chamadas áreas verdes urbanas e das metodologias para obtenção dos dados. O uso dos sensores teve precisão na identificação de áreas com solo exposto, asfaltada, com casas (telhados) que apresentaram contraste bem forte, facilitando a identificação dos aspectos constantes nos valores dos pixels na imagem satélite.

PALAVRAS-CHAVE: Áreas verdes, Imagens Orbitais, Vegetação arbórea. 


\section{MONITORING OF URBAN ARBORIZATION BY REMOTE SENSING IN A MUNICIPALITY IN THE BRAZILIAN SEMI-ARID ABSTRACT}

There are many ways to provide interaction between society in the urban environment, such as "green tree spaces" conceptualized as urban free space, composed of tree and shrub vegetation that provide softening for the environmental impacts of urbanization, where at least $70 \%$ of the area is permeable and accessible to the population. Thus, this study aimed to evaluate the use of remote sensing, based on satellite images, to characterize the arboreal green spaces in Petrolina, a municipality located in the Brazilian semiarid region. The evaluation was made using orbital images, classified by the segmentation technique, and validated. Then the green areas were quantified, and the green area index was calculated. This calculation includes all green areas, with native plants or not, which are considered in the composition of afforestation in the city of Petrolina to obtain leisure, thermal comfort, or urbanistic architecture. The index showed that there is $18,827 \mathrm{~m}^{2}$ of green area for each inhabitant of the city, which is considered high for the reality of the studied area, and this occurs due to the criteria for categorizing the so-called urban green areas and the methodologies for the obtaining of data. The use of sensors was accurate in the identification of areas with exposed, asphalted soil, with houses (roofs) that showed a very strong contrast, facilitating the identification of the constant aspects in the pixel values in the satellite image.

KEYWORDS: Green areas, tree vegetation, orbital images.

\section{INTRODUÇÃO}

Há muitas formas de proporcionar interação entre a sociedade no meio urbano, como a implantação das "áreas verdes", que são conceituadas como espaço livre urbano composto por vegetação arbórea e arbustiva, onde pelo menos $70 \%$ sendo com o solo permeável e área acessível à população. Elas proporcionam a amenização dos impactos ambientais da urbanização com condições ambientais favoráveis à saúde e diversão, as quais se remetem à existência de praças constituídas por parques e jardins, gerando um espaço agradável para a população (BARGOS; MATIAS, 2011; FARIA et al., 2013), proporcionando qualidade de vida, de maneira ecológica, estética e educativa, amenizando as condições maléficas da urbanização como ruído, calor e poluição (GOMES; AMORIM, 2003; COLTRO; MIRANDA, 2007).

Com isso, existe a responsabilidade do poder público em planejar e criar esses espaços verdes arbóreos nos municípios (SAVARD et al., 2000; ALVEY, 2006; BRUN et al., 2007). Para isso, deve haver o planejamento de áreas verdes urbanas, pois muitos locais presentes nas cidades não apresentam características que atendam ao conceito de área verde, consequentemente não possuem condições adequadas para as funções a que se destinam. Isso se dá por conta dos padrões urbanísticos criados de maneira inadequada por planejamentos desestruturados (FOLGARAIT, 1998; LOBRY DE BRUYN, 1999; ALMEIDA et al., 2007; LONDE; MENDES, 2014). É importante considerar as áreas verdes públicas, localizadas na zona urbana e que estão ligadas ao uso direto da população residente nessa área, as quais são compostas, geralmente, por parques, jardins, florestas, hortas comunitárias, estacionamentos ou praças (NUCCI, 2001).

Os espaços verdes urbanos favorecem ainda a conservação da biodiversidade, por abrigarem diferentes espécies, que atuam na polinização, dispersão de sementes e decomposição de material orgânico. É necessário identificar quais são realmente os espaços verdes, conforme o conceito estabelecido 
para evitar discordâncias no processo de avaliação dos mesmos, e não interferir nos dados coletados e nos resultados dos índices de vegetação, os quais as cidades, através do poder municipal, buscam sempre aumentar, pois através deles será quantificado o grau de arborização da área urbana (BARGOS; MATIAS, 2011; COSTA; COLESANTI, 2011).

Deve-se atentar para a forma de utilização desses espaços verdes e arbóreos, qual o público que frequenta os respectivos ambientes, a disponibilidade de área por habitante, distância dela até as residências, a propriedade, se é privada ou pública, e sua área total, para uma classificação adequada (HARDER et al., 2006). A fim de obter os índices de arborização, se faz necessário considerar somente as áreas verdes públicas situadas na zona urbana e com o uso direto da população residente da respectiva área.

A comunidade acadêmica vem desenvolvendo estudos voltados para a população relacionado a saúde, pois esses espaços verdes geram efeitos positivos em relação a longevidade, doenças cardiovasculares, obesidade, qualidade do sono, recuperação de doenças e desfechos de natalidade, além de gerar relaxamento para - corpo e a mente, promover contatos sociais, realizar atividades físicas, e proporcionar ar puro e úmido para a respiração (MEDEIROS, 2003; AMATOLOURENÇO et al., 2016).

A quantificação da arborização urbana pode ser estimada pelo índice de áreas verdes, que é expresso em termos de superfície área verde por habitante, ou através do percentual de áreas verdes, expresso pela relação do porcentual do solo ocupado pela arborização. A metragem recomendada pela Organização Mundial de Saúde (OMS) é de $12 \mathrm{~m}^{2}$ de área verde por habitante da zona urbana, porém a Sociedade Brasileira de Arborização Urbana (SBAU) propõe $15 \mathrm{~m}^{2}$ por habitante (HARDER et al., 2006).

Assim, nesse estudo objetivou-se avaliar o uso do sensoriamento remoto, a partir de imagens de satélite, para caracterizar os espaços verdes arbóreos de Petrolina, um município inserido no Semiárido brasileiro.

\section{MATERIAIS E MÉTODOS}

A pesquisa teve como base o método quantitativo, apresentando resultados que podem ser quantificados, e possibilita a medição de informações sobre um assunto que já é conhecido, demonstrando assim, dados coletados com uma natureza mais estatística, sendo expostos em forma de gráficos, tabelas, mapas, etc.

A pesquisa foi desenvolvida no município de Petrolina - PE, inserido na região semiárida do Brasil. A região semiárida segundo Ab'sáber (2010), é uma região com depressões interplanálticas, com planícies por erosão devido às grandes extensões de pediplanos, áreas com fraca decomposição de rochas, por conta das alterações mínimas, de 0 a $3 \mathrm{~mm}$. Há a ocorrência de rochas expostas (cabeços, lajedos e malhas) dentro da Caatinga, sendo que a drenagem ocorre de forma sazonal nas chuvas da região. Segundo Andrade-Lima (1981), a Caatinga possui uma grande variedade de tipos vegetacionais, com um elevado número de espécies e locais da vegetação ainda preservados, que incluem um número expressivo de táxons raros e endêmicos. As condições do clima semiárido, são com precipitação que varia de 500 a $800 \mathrm{~mm}$ por ano, as temperaturas variam em média a altas faixas de 23 a $27 \stackrel{\circ}{\circ}$, com umidade do ar inferior a $50 \%$, possuindo evapotranspiração alta que chega a $1.500 \mathrm{~mm}$ a 2000 ao ano (SILVA et al., 2017). 
O município de Petrolina possui uma população com cerca de 343.865 pessoas numa área igual a $4.561,870 \mathrm{~km}^{2}$ (Figura 1), resultando em densidade demográfica igual a $64,44 \mathrm{hab} \cdot \mathrm{km}^{-2}$. O Índice de desenvolvimento humano municipal vem aumentando, sendo igual a 0,471 no ano de 1991, passando a 0,580 em 2000, e para em 0,697 em 2010 (IBGE ,2020).

FIGURA 1: Mapa de Localização da Cidade de Petrolina - PE

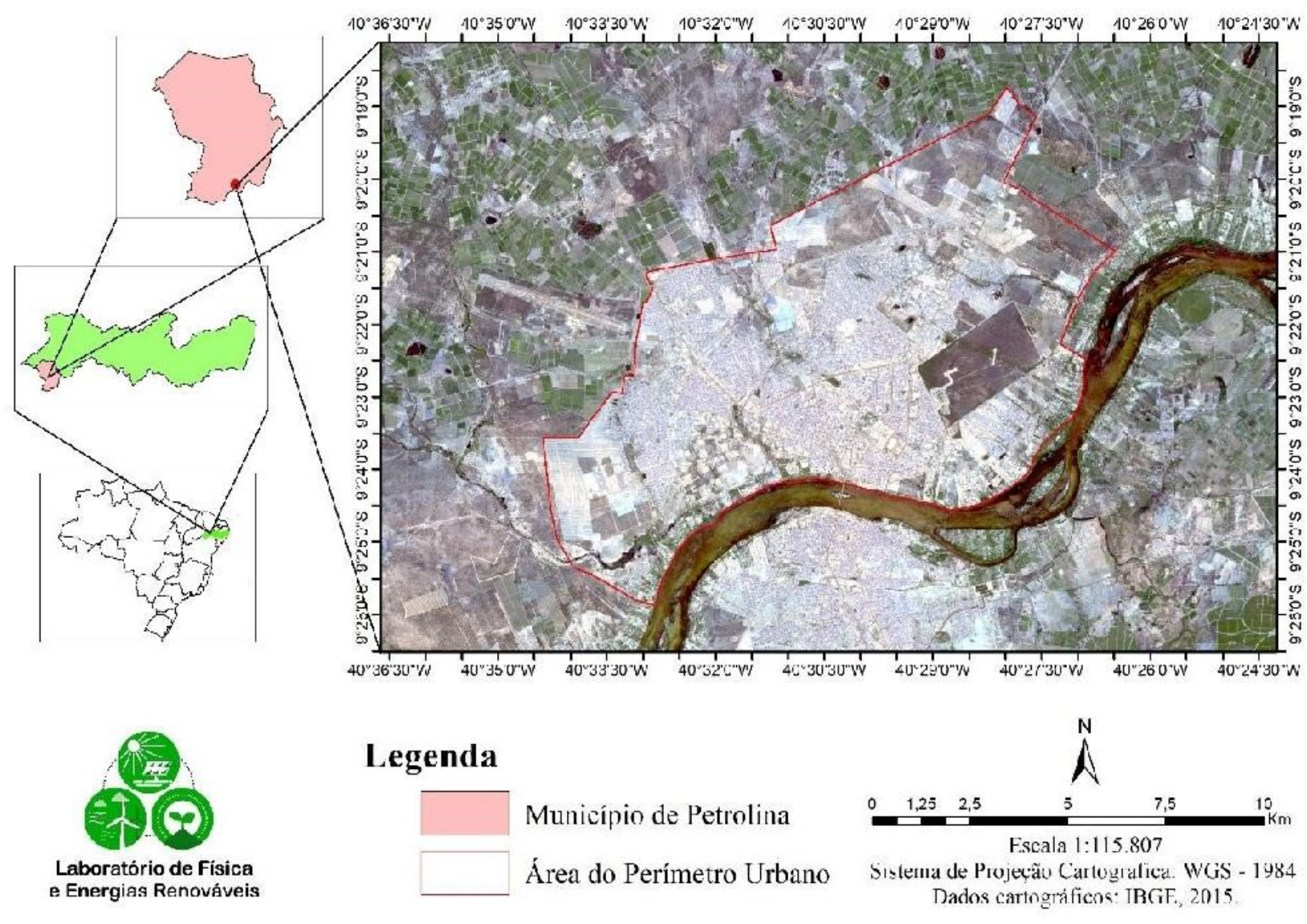

Fonte: Os autores (2021)

Para o estudo foi selecionada a cena (órbita/ponto) 22972/9 do sensor Multi Spectral Instrument (MSI), com data de passagem de 20 de dezembro de 2018, do satélite Sentinel-2, disponibilizada pela Agência Espacial Europeia - ESA, com resolução espacial de 10 metros e cálculos de refletância. $A$ escolha da data da cena foi feita no período com ausência de nuvens, coincidindo com a data em que foram coletados os dados em campo para validação da imagem. (BEZERRA, 2018). A cena foi adquirida do Serviço Geológico dos Estados Unidos - USGS (https://store.usgs.gov/).

A imagem foi submetida à técnica de segmentação, com o uso do software ARCGIS 10.2 (versão demonstrativa), que consiste em agrupar regiões a partir de pixels individuais, propondo um agrupamento de regiões baseado no conceito de região vizinha mais similar, que acarreta na junção espacial de pares semelhantes, quando são definidos os contornos, fazendo uma base com propriedades dos níveis de cinza, onde as classificações vêm por valores de similaridade espectral e 0 tamanho da área. Possibilitando, desta forma, por meio das imagens de satélite, a 
classificação da vegetação, dos usos do solo, tipos de rochas, dentre outros (ERTHAL et al., 1991; BORGES; SILVA, 2009).

A partir da segmentação, as áreas foram classificadas conforme os tipos de uso e ocupação das terras observadas em campo (Figura 2): áreas de corpo de água foram associadas aos pontos de rio e lagos; áreas de solo exposto incluíram as áreas onde o solo encontrava-se totalmente descoberto, devido à ausência de cobertura vegetal; as áreas urbanas incluem os locais com casas, prédios ruas e vias pavimentadas; as área de vegetação de caatinga compreenderam todos os locais com áreas de vegetação nativa que estão preservadas por serem propriedades privadas, reservadas para loteamentos futuros e, finalmente, o espaço verde urbano compreendendo os locais associados à jardins, parques, praças e vias arborizadas.

FIGURA 2: Imagens ilustrativas das classes do uso e cobertura.

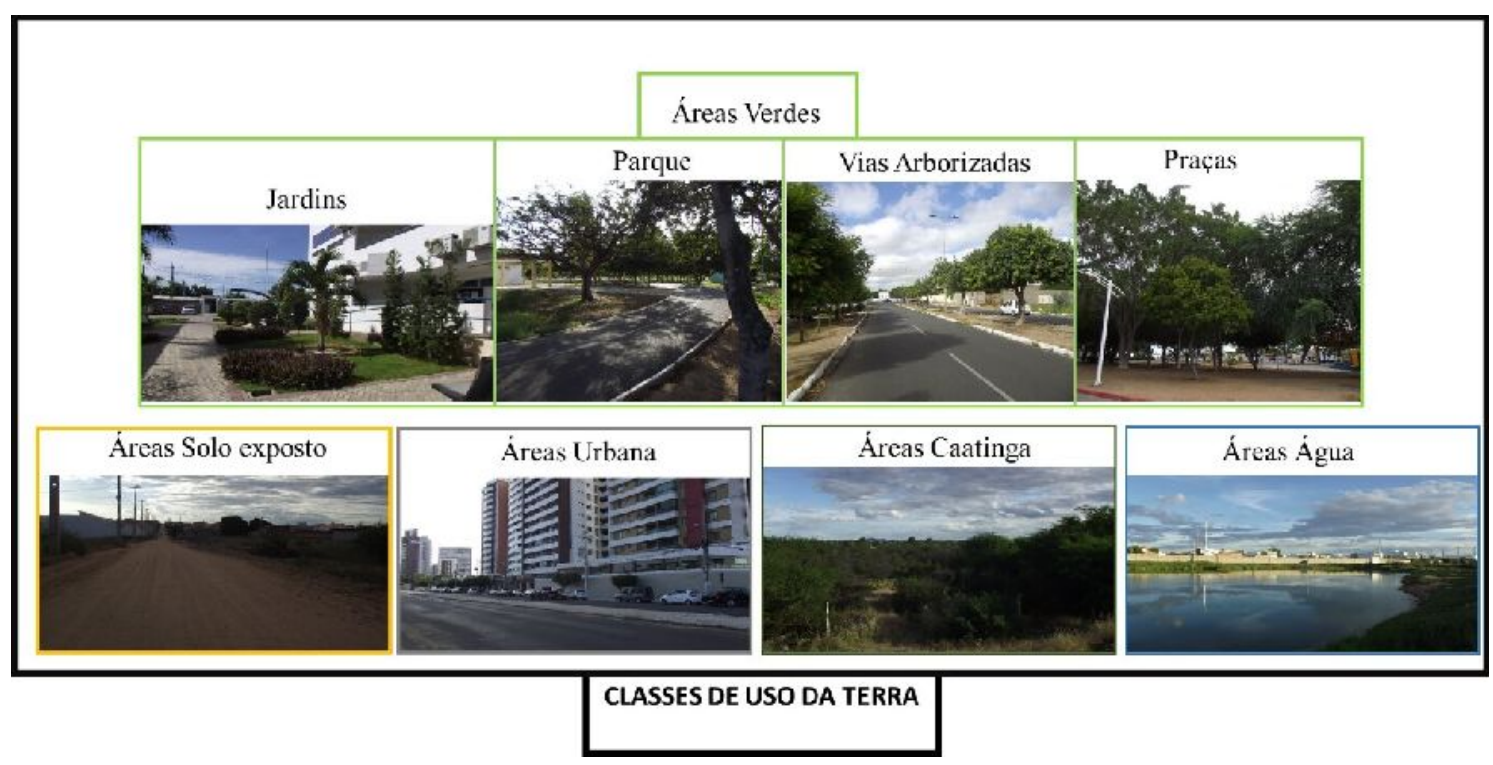

Fonte: Os autores (2021)

Para validar a classificação obtida por meio da segmentação, foi aplicado o teste estatístico do coeficiente KAPPA (Equação 1), que tem o propósito de estabelecer um grau de concordância entre duas amostras independentes: a classificação em forma de mapa e os pontos coletados de acordo com o uso da terra. Para tanto, foram coletados 74 pontos, distribuídos espacialmente de forma aleatória por toda área urbana do município (Figura 3), e obtidos dados em cada ponto para ser aplicado o teste estatístico KAPPA (Equação 1). Os valores de concordância do KAPPA fornecem o grau de compatibilidade das variáveis envolvidas (SILVA; PAES, 2012).

$K A P P A=\frac{P(O)-P(E)}{1-P(E)}$

(Equação 1)

Em que:

$P(O)$ é a proporção observada de concordância, que corresponde a soma das respostas concordantes dividida pelo total, e $P(E)$ é a proporção esperada de ENCICLOPÉDIA BIOSFERA, Centro Científico Conhecer - Jandaia-GO, v. 18 n.36; p. 246 
concordâncias, que corresponde a soma dos valores esperados das respostas concordantes dividida pelo total.

FIGURA 3: Distribuição dos pontos de coleta de dados em campo.

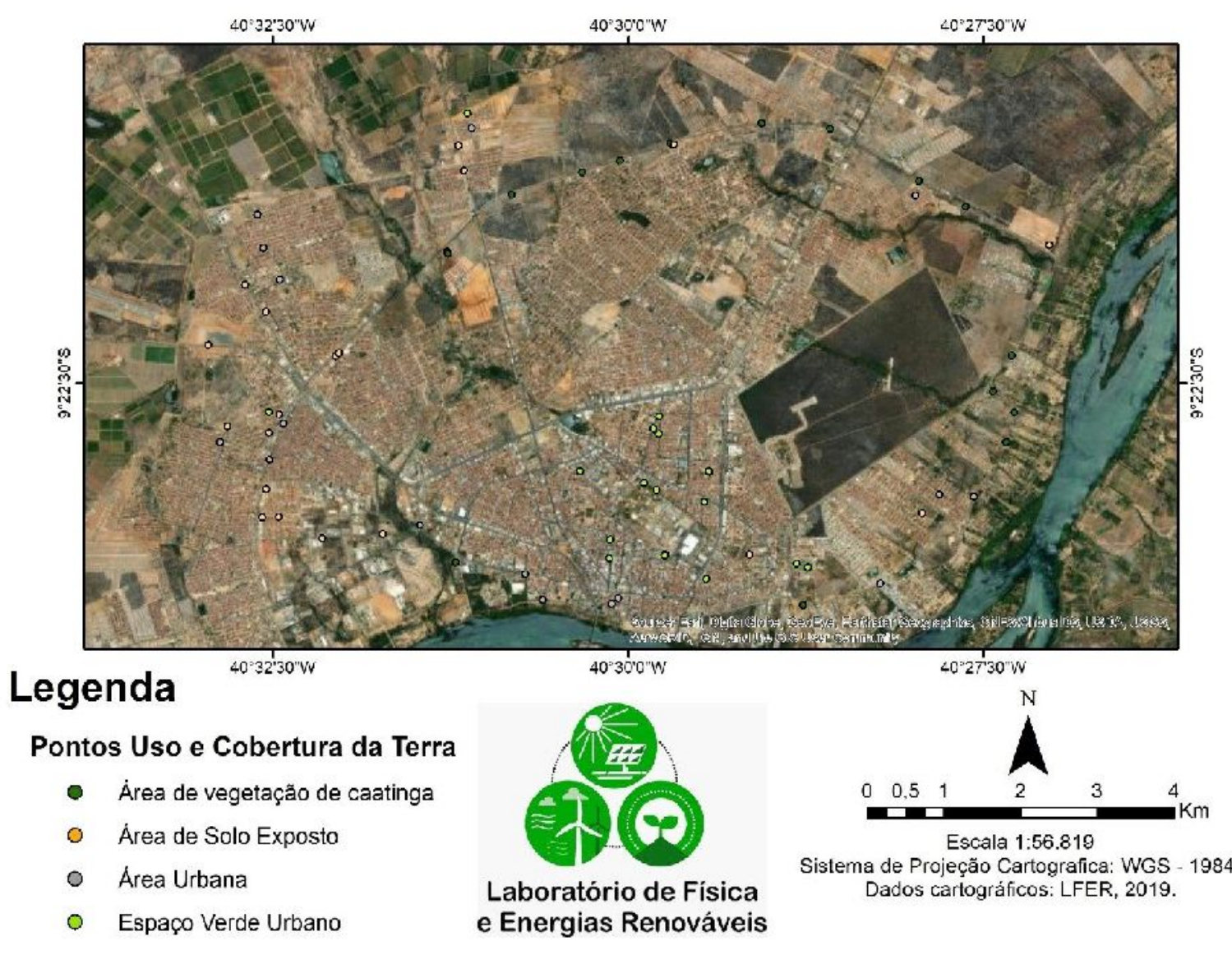

Fonte: Os autores (2021)

O coeficiente KAPPA é uma medida inter observador que permite avaliar a concordância dos dados coletados em campo com os dados obtidos na imagem de satélite (SILVA; PAES, 2012). Os valores podem ser interpretados conforme categorização apresentada no Quadro 1.

QUADRO 1 - Grau de concordância entre imagem de satélite e avaliação de campo

\begin{tabular}{|c|c|}
\hline Valores do coeficiente KAPPA & Grau de concordância \\
\hline$<0$ & Ausente \\
\hline 0 a 19 & Pobre \\
\hline 20 a 39 & Leve \\
\hline 40 a 59 & Moderada \\
\hline 60 a 79 & Substantiva \\
\hline 80 a 100 & Quase perfeita \\
\hline
\end{tabular}

Fonte: SILVA;PAES (2012). 
Após a validação da classificação da imagem, as áreas classificadas como "áreas verdes" foram delimitadas e totalizadas em metros quadrados. Finalmente, foi calculado o índice de áreas verdes (IAV) (Equação 2) (SILVA, et al., 2016), que é a razão entre o somatório das áreas verdes da cidade de Petrolina (AV), e seu número de habitantes.

$$
I A V=\frac{\sum A V}{H}
$$

Onde, AV é o somatório das áreas verdes em metros quadrados e H é o número de habitantes.

\section{RESULTADOS E DISCUSSÃO}

O mapeamento resultante do tratamento e processo de segmentação realizado na imagem com a cidade de Petrolina (Figura 4), mostra que a distribuição com maior densidade das classes de área urbana e áreas verdes são concentradas no centro da cidade, nas áreas de caatinga e solo exposto são mais concentrados nos bairros periféricos. Desta forma, outro aspecto a ser observado em campo é a presença do solo exposto que corresponde a cerca de $20 \%$ da área total delimitada no mapa, por conta da infraestrutura inacabada, pois muitos bairros da cidade estão sendo loteados e outros não possuem pavimentação nas ruas e vias de acesso. Demonstrando assim, a necessidade de um planejamento correto para implementar mais áreas verdes na cidade de Petrolina, principalmente nos bairros.

FIGURA 4: Mapa de uso e cobertura das terras perímetro urbano de Petrolina, PE.

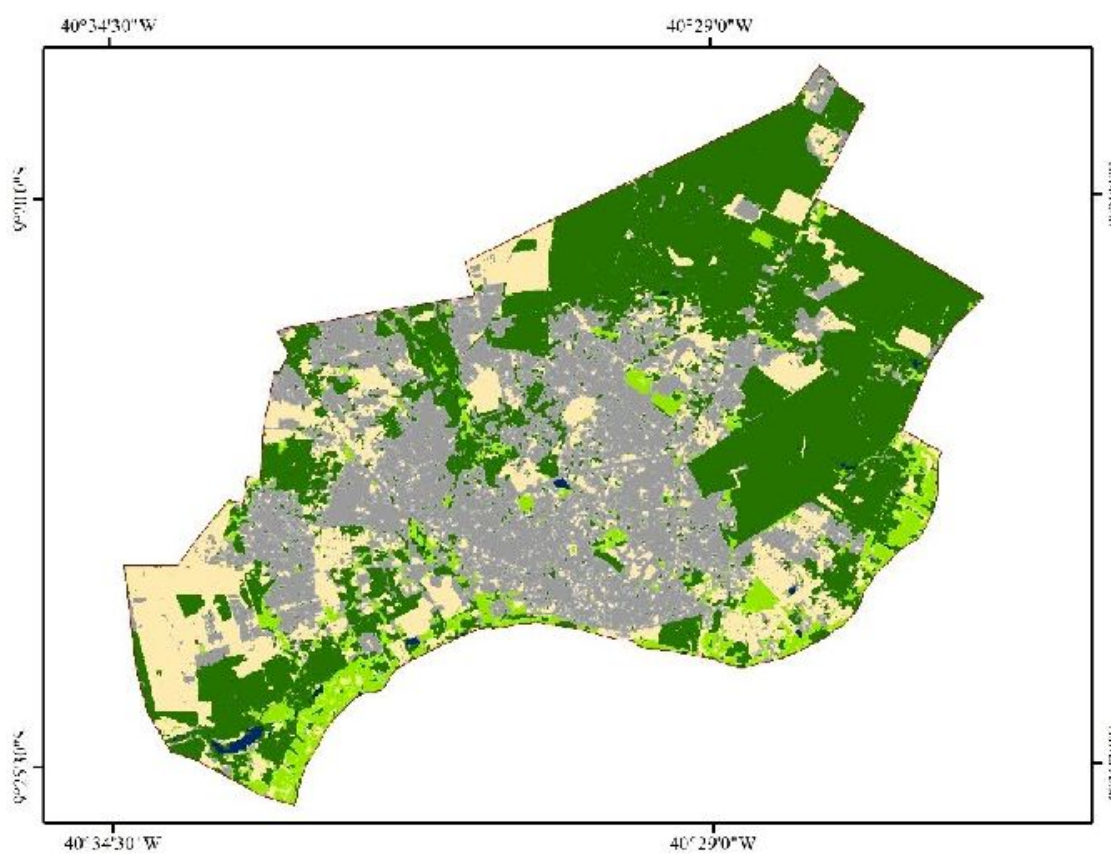

\section{Legenda}

Cidade de Petrolina - PE

$\square$ Área do Perímetro Erbano

Uso e Cobertura da Terra

- Árca de Corpo de Água

Área de veggetação Caatinga

Árca de Solo Exposto

¿ Espaço Verde Urbano

Árca Urbana

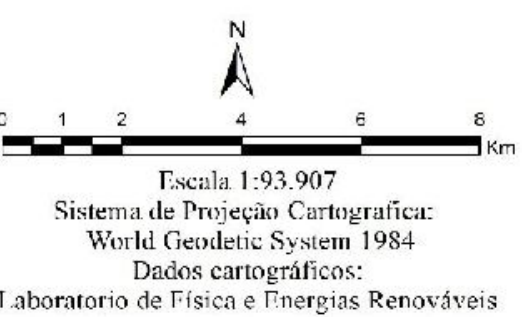

Fonte: autores (2021). 
O teste KAPPA, obtido por meio da aplicação dos dados de campo e do mapa elaborado a partir das imagens de satélite, atribuiu um grau de concordância de $86 \%$, classificada como "quase perfeita". Este resultado explica que o mapa consegue representar a realidade presente em campo, validando a imagem gerada inicialmente para o estudo de arborização. Esse valor é considerado alto para a realidade da área estudada, devido a uma má distribuição.

Por ser mais concentrada em locais específicos no centro da cidade, algumas áreas também são consideradas áreas verdes, possuindo espécies nativas incorporadas em avenidas, ruas e até em praças, onde são desenvolvidas práticas esportivas, parques de recreação e ambiente de lazer e convivência durante o quotidiano da população. Desta forma, há uma certa dificuldade para diferenciar a área verde urbana da área de caatinga já que as mesmas características morfológicas das espécies são compartilhadas nas duas classes.

As técnicas aplicadas conseguem fazer boa identificação das áreas por conta do solo exposto, asfalto e telhados das casas terem contraste bem forte, facilitando a identificação dos aspectos constantes nos valores dos pixels na imagem satélite. A distribuição das áreas por classes de uso e ocupação da terra demonstra que as áreas verdes têm pouca porcentagem, com cerca de $8 \%$, concentrando-se no centro da cidade mostrando que as áreas periféricas da cidade ainda não tiveram trabalhos iniciados voltados para a arborização. Seguindo a classificação, vêm as áreas de solo exposto, com $20 \%$, as áreas urbanas, com $30 \%$ e as áreas de Caatinga, que ocupa $41 \%$.

Após a aplicação dos dados coletados na fórmula para calcular o índice de áreas verdes, obteve-se $18,827 \mathrm{~m}^{2}$ de área verde para cada habitante da cidade. Com base na discussão do Cavalheiro e Del Picchia (1992), sobre a existência do índice de $12 \mathrm{~m}^{2}$ de área verde/habitante considerado ideal pela OMS e 15 $\mathrm{m}^{2} /$ habitante pela Sociedade Brasileira de Arborização Urbana, e fazendo comparação ao índice obtido na cidade de Petrolina, é possível considerar um valor positivo, porém, com base na coleta de dados em campo, os locais visitados, demonstram a falta de planejamento e distribuição correta destes espaços verdes, pois nem todos são favorecidos por esse índice de arborização.

De acordo também, com os estudos de Lucon et al., (2013), que discute sobre os valores de áreas verdes, apresentando um resultado de $9,55 \mathrm{~m}^{2}$ de IAVT para a cidade de Curitiba (PR) e 6,29 $\mathrm{m}^{2}$ em Bauru (SP) de área verde/hab, relacionando com o presente projeto, o valor obtido é considerado alto para a realidade da área estudada. Essa diferença nos valores de IAV ocorre por conta dos critérios para categorização das chamadas áreas verdes urbanas e das metodologias para obtenção dos dados.

Este trabalho teve desenvolvimento com imagens de satélite retratando a situação em dezembro de 2018, porém novos dados poderão ser gerados e comparados para análise do desenvolvimento das áreas verdes na cidade futuro.

\section{CONCLUSÕES}

A cidade de Petrolina apresenta áreas diversificadas em relação à arborização, como solo exposto, área urbana, caatinga e espaço verde. Esse último foi possível obter o valor, por meio do uso de sensoriamento remoto e das imagens de satélite, com o levantamento da caracterização, a nível de arborização urbana, mostrando que, o método utilizado, caracterizou adequadamente, a distribuição dos tipos de uso e cobertura da terra obtidos nos resultados, podendo ser utilizado para 
políticas públicas e planejamento urbano de uma cidade, gerando melhorias na infraestrutura e na qualidade de vida da população.

\section{AGRADECIMENTO}

O presente trabalho foi realizado com apoio da Coordenação de Aperfeiçoamento de Pessoal de Nível Superior -Brasil (CAPES) - Código de Financiamento 001 ao Programa de Pós-Graduação em Ciência e Tecnologia Ambiental da Universidade de Pernambuco.

\section{REFERÊNCIAS}

AB'SÁBER, A. N. 2003. Os domínios de Natureza do Brasil: Potencialidades paisagísticas - São Paulo: Ateliê Editorial.

ALMEIDA, F. S.; QUEIROZ, J. M.; MAYHE-NUNES, A.J.; Distribuição e abundância de ninhos de Solenopsis invicta Buren (Hymenoptera: Formicidae) em um agroecossistema diversificado sob manejo orgânico. Floresta e Ambiente, n.14, 3444, $2007 \quad$ Disponível em: <https://www.floram.org/article/588e2216e710ab87018b4647 >.

ALVEY, A. A. Promoting and preserving biodiversity in the urban forest. Urban Forestry \& Urban Greening. v. 5, n.4, 2006, pg.195-201. Disponível em: < https://doi.org/10.1016/j.ufug.2006.09.003>. doi:10.1016/j.ufug.2006.09.003

AMATO-LOURENCO, L. F.; MOREIRA, T. C. L.; ARANTES, B. L.; SILVA FILHO, D. F.; MAUAD, T. Metrópoles, cobertura vegetal, áreas verdes e saúde. ESTUDOS AVANÇADOS, v.30, n.86, 2016. Disponível em: < https://doi.org/10.1590/S010340142016.00100008>. doi: 10.4215/RM2009.0816.0015

BARGOS, D. C.; MATIAS, L. F. 2011. Áreas verdes urbanas: um estudo de revisão e proposta conceitual. REVSBAU, v.6, n.3, 2011, p.172-188.

BEZERRA, U. A.; OLIVEIRA, L. M. M.; CANDEIAS, A. L. B; SILVA, B B.; LEITE, A. C. L. S.; SILVA, L. T. M. S. Comparativo do Índice de Vegetação de Diferença Normalizada (NDVI) entre os Sensores OLI - Satélite Landsat-8 e MSI - Satélite Sentinel-2 em Região Semiárida. Anuário do Instituto de Geociências - UFRJ. ISSN 0101-9759 e ISSN 1982-3908, Vol. 41 - 3, 2018, p. 167-177.

BORGES, E. F.; SILVA, A. B. Técnicas de segmentação de imagens e classificação por região: mapeamento da cobertura vegetal e uso do solo, Mucugê-BA. Mercator, v. $8, \quad$ n. 17, 2009, p. 209-220. Disponível em: < http://www.mercator.ufc.br/mercator/article/view/258>. doi: 10.4215/RM2009.0816.0015

BRUN, F. G. K., LINK, D., BRUN, E. J. O emprego da arborização na manutenção da biodiversidade de fauna em áreas urbanas. Revista da Sociedade Brasileira de Arborização Urbana. v.2, n.1, 2007. Disponível em: < http://dx.doi.org/10.5380/revsbau.v2i1.66253>.

CASTELleTTI, C. H. M., SILVA, J. M. C., TABARELLI, M. \& A. M. M. SANTOS. Quanto ainda resta da Caatinga? Uma estimativa preliminar. In: J.M.C. Silva, M. 
Tabarelli, M.T. Fonseca \& L.V. Lins (orgs.). Biodiversidade da Caatinga: áreas e ações prioritárias para a conservação. 2004, p. 91-100. Ministério do Meio Ambiente, Brasília.

CAVALHEIRO, F.; DEL PICCHIA, P. C. D. Áreas verdes: conceitos, objetivos e diretrizes para o planejamento. In: $1^{\circ}$ congresso brasileiro sobre arborização urbana. Encontro Nacional sobre Arborização Urbana, 4., Vitória - ES. Anais... p. 29-38, 1992.

COLTRO, E. M.; MIRANDA, G. M. Levantamento da arborização urbana pública de Irati-Pr e sua influência na qualidade de vida de seus habitantes. Revista Eletrônica Lato Sensu, v.2, n.1, p.1-22, 2007.

COSTA, R. G. S.; COLESANTI, M. M. A Contribuição da Percepção Ambiental nos Estudos das Áreas Verdes. RA'EGA. Curitiba: UFPR, v.22, 2011, p. 238-251. Disponível em: < https://revistas.ufpr.br/raega/article/view/21774/14173>

DANTAS, I. C.; SOUZA, C. M. C. Arborização urbana na cidade de Campina Grande - PB: Inventário e suas espécies. Revista de Biologia e Ciências da Terra Universidade da Paraíba, Campina Grande. 2004. Disponível em: $<$ http://joaootavio.com.br/bioterra/workspace/uploads/artigos/arborizaurbana515646a391755.pdf>.

ERTHAL, G. J.; FONSECA, L. M. G.; BINS, L. S. A.; VELASCO, F. R. D.; MONTEIRO, A. M. V. 1991. Um sistema de segmentação e classificação de Imagens de Satelite. Anais... IV Simpósio Brasileiro de Computação Gráfica e Processamento de imagens.

GOMES M. A. S., AMORIM M. C. C. T. Arborização e conforto térmico no espaço urbano: estudo de caso nas praças públicas de Presidente Prudente (SP). Caminhos da Geografia, v.7, n.10, p.94-106.2003.

HARDER, I. C. F; RIBEIRO, R. C. S; TAVARES, A. R. Índices de Área Verde e cobertura vegetal para as praças do município de vinhedo, SP. Sociedade de Investigações Florestais. R. Árvore, Viçosa-MG, v.30, n.2, p.277-282, 2006. Disponível em: < https://doi.org/10.14393/SN-v33-2021-57464>. doi: 10.14393/SNv33-2021-57464

IBGE - Instituto Brasileiro de Geografia e Estatística . Censo Brasileiro de 2010. Rio de Janeiro: IBGE, 2020. Disponível em:< https://www.ibge.gov.br/cidades-eestados/pe/petrolina.html?> Acesso em: 26 abril. 2020.

LUCON, T. N.; PRADO FILHO J. F.; SOBREIRA F. G. Índice e percentual de áreas verdes para o perímetro urbano de ouro preto - MG. REVSBAU, v.8, n.3, p. 63-78, 2013. Disponível em: < http://dx.doi.org/10.5380/revsbau.v8i3.66430>.

LOBRY de BRUYN, L.A. Ants as bioindicators of soil function in rural environments. Agriculture, Ecosystems and Environment, v.74, p.425-441, 1999. Disponível em: $<$ https://doi.org/10.1016/S0167-8809(99)00046-8>.

doi:10.1016/s01678809(99)00046-8 
MEDEIROS, E. M. F. 2003. Estética do Apocalipse: (re) considerações acerca da (des) arborização urbana de Natal e seu contributo a saúde pública. Natal.

$\mathrm{NUCCl}$, J. C. Qualidade ambiental e adensamento urbano: um estudo de ecologia e planejamento da paisagem aplicado ao distrito de Santa Cecília (msp). São Paulo: USP, FFLCH. 2001.

ROCHA, J. R.; WERLANG, M. K. Índice de cobertura vegetal em Santa Maria: o caso do Bairro Centro. Ciência e Natura,V.27, N. 2, p. 85 - 99, 2005. Disponível em: < https://periodicos.ufsm.br/cienciaenatura/article/view/9680>. doi: https://doi.org/10.5902/2179460X9680

SAMPAIO, E. V. S. B., A.M. GIULIETTI, J. VIRGÍNIO; C.F.L. GAMARRA ROJAS. Vegetação e flora da Caatinga. Associação Plantas do Nordeste e Centro Nordestino de Informação sobre Plantas, Recife, Brasil. 2002.

SANCHOTENE, M. do C.C. Desenvolvimento e perspectivas da arborização urbana no Brasil. In: Congresso Brasileiro de Arborização Urbana, 2, 1994. São Luís - Ma. Anais... São Luís, Sociedade Brasileira de Arborização Urbana.

SAVARD J. L., CLERGEAU P., MENNECHEZ G. 2000. Biodiversity concepts and urban ecosystems. Landscape and Urban Planning. Disponível em: < https://scihub.se/10.1016/s0169-2046(00)00037-2 > . doi:10.1016/s0169-2046(00)00037-2

SILVA, A. D. P.; SANTOS, A. F.; OLIVEIRA, L. M. Índices de área verde e cobertura vegetal das praças públicas da cidade de Gurupi, TO. FLORESTA. v. 46, n. 3, 2016. Disponível em: <http://dx.doi.org/10.5380/rf.v46i3.40052>. doi: 10.5380/rf.v46i3.40052

SILVA, P. F.; LIMA, J. R. S.; ANTONINO, A. C. D. SOUZA, R.; SOUZA, E. S.; SILVA, J. I.; ALVES, E. M. Seasonal patterns of carbon dioxide, water and energy fluxes over the Caatinga and grassland in the semi-arid region of Brazil. Journal of Arid Environments. v.147, p.71 - 82, 2017. Disponível em: < http://dx.doi.org/10.1016/j.jaridenv.2017.09.003>. doi: 10.1016/j.jaridenv.2017.09.003

SILVA, R S.; PAES, Â. T. 2012. Por dentro da estatística. Educação Continua em Saúde - EINSTEIN. São Paulo, v. 10, n.4, p. 165 - 6, 2012. Disponível em: < http://apps.einstein.br/revista/arquivos/PDF/2715-165-166.pdf>.

VIDAL, M.; GONÇALVES, W. Curso de paisagismo. Viçosa, MG: UFV.1999. 